I have examined. They will come to the criticism of my results with fuller materials than are available to me here, but so far as these materials enable me to form an opinion, the result is against the existence of a common periodicity in the sun-spots and in the American rainfall within the temperate zone.

Allanton, Lanarkshire, November 4 W. W. Hunter

\section{Contribution to the Sun-spot Theory of Rainfall}

THE Lucknow Meteorological Observatory has been estab. lished since $\mathbf{1} 868$, and regular observations have been recorded since that year under my superintendence.

In NATURE of Deceraber 12, I872, Mr. Lockyer published a notice of Mr. Meldrum's discovery of the coincidence between the maximum and minimum sun-spot periods, and the maximum and minimum rainfall in certain places. After reading it I examined the annual rainfall at Lucknow from 1868 to $\mathbf{1 8 7 2}$, and found that there was reason to believe that the rainfall at Lucknow followed the same cycle as that of the sun-spots. The figures were :-

$\begin{array}{llllllll}1868 & \ldots & \ldots & \ldots & \ldots & \ldots & 27 \cdot 6 & \text { inches. } \\ 1869 & \ldots & \ldots & \ldots & \ldots & \ldots & 4 \mathrm{r} \cdot 9 & , \\ 1870 & \ldots & \ldots & \ldots & \ldots & \ldots & 64 \cdot 6 & , \\ 187 \mathrm{r} & \ldots & \ldots & \ldots & \ldots & \ldots & 65 \cdot 0 & , " \\ 1872 & \ldots & \ldots & \ldots & \ldots & \ldots & 41 \cdot 4 & \end{array}$

The equal amount of rainfall (4I inches) on both sides of the maximum fall of 1870 and $187 \mathrm{r}$ was very striking, and as there was a rise in the rainfall from 1868 to $1870-71$, and after that a decrease, and having just read Meldrum's discovery, I conjectured that the annual rainfall would continue to decrease till it reached its minimum. In my annual abstract, which I submitted to Government in April, 1873, and on the slender evidence of five year's rainfall, I ventured to state that if Meldrum's law be true, we had in Lucknow lately passed the period of maximum rainfall, and were descending towards a minimum, si that during 1877 , 1878 , and 1879 there would be a scarcity of rain, and in one of those years the minimum rainfall of the cycle would occur. I am now able to give the annual rainfall of almost a complete cycle, and the figures will speak for themselves:-

\begin{tabular}{|c|c|c|c|c|c|c|}
\hline 1868 & $\ldots$ & $\ldots$ & $\ldots$ & $\ldots$ & 276 & \\
\hline 1869 & $\ldots$ & $\ldots$ & $\ldots$ & $\ldots$ & 419 & \\
\hline 1870 & $\ldots$ & $\ldots$ & $\ldots$ & $\ldots$ & 64.6 & \\
\hline $187 \mathrm{r}$ & $\ldots$ & $\ldots$ & $\ldots$ & $\ldots$ & $65^{\circ} 0$ & \\
\hline 1872 & $\ldots$ & $\ldots$ &.. & $\ldots$ & $4 I^{4} 4$ & Inches of \\
\hline 1873 & $\ldots$ & $\ldots$ & $\ldots$ & $\ldots$ & $35^{\circ} x$ & rainfăll \\
\hline 1874 & $\ldots$ & $\ldots$ & $\ldots$ & $\ldots$ & $5 I^{\prime} 4$ & in Lucknow. \\
\hline 1875 & $\ldots$ & $\ldots$ & $\ldots$ & $\ldots$ & 43.5 & \\
\hline 1876 & $\ldots$ & $\ldots$ & $\ldots$ & $\ldots$ & $23 \cdot 6$ & \\
\hline 1877 & $\ldots$ & $\ldots$ & $\ldots$ & $\cdots$ & 117 & \\
\hline
\end{tabular}

This is October 22, 1877 , and the total fall up to date has been orly ir' 7 inches, about a third of which fell in the months of January, February, and March. The fall during the rainy season of 1877 has been so small that great fear of a famine has been felt. I considered Meldrum's discovery so important that at the end of my annual abstract of meteorological observations for 1872 , I inserted a long abstract of Mr. Lockyer's article in NATURE, in order to make the theory more widely known.

I believe meteorologists are on the track of a most important law. I would not expect the maximum and minimum rainfalls in every place to coincide with the sun-spot maximum and minimum so completely as that given above. Possibly in some places the figures might be reversed, owing to a changed direction in the -water-bearing currents of the atmosphere; but that the changes occurring in the sun have a direct influence on rainfall there cannot, I think, be any doubt.

E. BONAVIA

Lucknow, October 22

\section{The Radiometer and its Lessons}

I wish that Prof. G. C. Foster had been more explicit in his answer to my letter ; for as it is I cannot understand to what "variations of density" he refers. So far as I know there are no variations of density in the gas in question except those which arise from variations of temperature; but these variations of density certainly do not affect the rate at which heat diffuses into and through the gas, for this rate is independent of the density and for the same gas depend only on the absolute temperature and on the degradation of temperature in the direction in which the diffusion takes place. The variations of temperature do affect the rate of communication but only in proportion to the square root of the absolute temperature, and hence, in the case of the radiometer, only to an inappreciable extent.

It is obvious that the law of diffusion holds good only so long as the gas is undisturbed by convection currents. Such currents, which certainly exist, increase the rate at which heat is communicated to the gas, that is to say, the hot surface instead of being exposed to the action of still air is exposed to a wind which tends to increase the rate of cooling. But the velocity of the wind does not increase with the rarefaction, and the cooling effect of a wind of a certain velocity does increase with the density of the air. Hence, as I pointed out in my first paper, the motion of the air will favour the force resulting from the communication of heat less and less as the rarefaction is increased.

As regards Mr. Johnstone Stoney's theory. The post which brought me this week's NATURE brought me also a paper from Mr. Stoney, on which I venture to comment. In doing this, however, I may say that I have no wish to criticise what Mr. Stoney has written. The fact that Mr. Stoney has in no way referred to my work, although I preceded him by some two years, has relieved me from all obligation to discuss Mr. Stoney's theory ; and I certainly should not do so now were it not that, as Prof. Foster has instanced this theory as disproving what $\mathcal{I}$ believe to be the truth, I feel bound either to show wherein it is wrong or acknowledge my inability to do so.

In the paper which I have just received, $1 \mathrm{Mr}$. Stoney start $\mathrm{s}$ with an assumption that, but for the effect of gravitation, "a flat stratum of gas in contact with a hot surface, A," and "everywhere subject to the same presaure" can exist in a state of equilibrium "except at the limits," without any passage of heat from the hotter to the colder part, although "within the stratum the temperature gradually decreases, from within outwards, from $\theta_{1}$ the temperatire of $\mathrm{A}$ to $\theta_{2}$ the temparature of the surrounding gas."

In support of this assumption I cann t find that any proot is offered except that which is contained in the following portion of a sentence:--"We know, from familiar experiments, which show gases to be bad conductors of heat, that after the brief interval of adjustment a permanent state would ensue in which there would be no further change of density, or motion of heat, except by radiation."

Now this assumption and the statement in support of it-in both of which Mr. Stoney seems to have ignored the very existence of diffusion of heat in gases-are contrary to all experience as well as to the deductions from the linetic theory of gases; for it follows directly from the kinetic theory, and has been abundantly established by experiment, that under no circumstances can there exist a variation in the temperature of a continuous layer of gas without heat diffusing from the hot ter to the cooler part.

I think that I need say no more. This assumed condition of gas forms the base of all Mr. Stoney's reasoning, and although in a subsequent part of his paper he appears to me to have arrived at deductions which contradict his fundamental assumption, still this assumption may be held accountable for the anomalies which he has found.

November 17

I BEG to call the attention of the readers of NATURB to the following passage at the commencement of Mr. Crookes's lecture at the Royal Institution on February II, 1876, "On the Mechanical Action of Light" :-

"To generate motion has been found a characteristic common, with one exception, to all the phases of physical force." [Illustrations are then given of the production of motion by heat, magnetism, electricity, gravitation, sound, and chemical force.]

"But light, in some respects the highest of the powers of nature, has not hitherto been found capable of direct conversion into motion; and such an exception cannot but be regarded as a singular anomaly.

"This anomaly the researches which I am about to bring before you have now removed; and, like the other forms of force, light is found to be capable of direct conversion into motion, and of being most delicately and accurately measured by the amount of motion thus produced."

I cannot but suppose that Mr. Crookes and Prof. Carey Foster have alike forgotten the existence of this passage. If it does not convey an interpretation of the phenomena of the radiometer which is now admitted on all hands to be wrong, and imply a claim to the discovery of "a new mode of force," I am incapable of understanding the meaning of words.

I may add that one alter another of my eminent scientific

x "On the Penetration of Heat across Layers of Gas," Scientific Transactions of the Royal Dublin Society, November, 1877 . 